\title{
TELENCEPHALON VASCULARITY IN DOG (Canis lupus f. familiaris)
}

\author{
Krzysztof Kirkiłło-Stacewicz*, Włodzimierz Nowicki, Jan Wach \\ UTPUniversity of Science and Technology, Faculty of Animal Breeding and Biology, Department of Physiology, Zoophysiotherapy and Animal \\ Feeding, Mazowiecka 28, 85-084 Bydgoszcz, Poland \\ ${ }^{*}$ Corresponding author, E-mail: krzysztof.stacewicz@o2.pl
}

\begin{abstract}
The studies of the vascularization of the cerebrum in dog were performed on 80 cerebral hemispheres. It was found that the middle cerebral artery is the strongest vessel supplying blood to the cerebrum. The artery gets divided into ten permanent branches. Two olfactory arteries supply the region of the cerebrum located on the border between the old and the new cortex. The other eight supply the region of the new cortex: three branches aiming at the frontal lobe, two branches at the parietal lobe and three temporal branches aiming at temporal area. The frontal, parietal and temporal branches descended independently from the main trunk of the middle cerebral artery or formed a common trunk. Common trunks for respective groups of branches have been described as the rostral, dorsal and caudal middle cerebral artery. In $2.5 \%$ of cases there were two independent branches of the middle cerebral artery extending from the rostral cerebral artery.
\end{abstract}

Key words: brain arteries; dog; vascularity; variability

\section{Introduction}

A review of the literature shows that the basic morphological publications in the field of vascularization of the brain were provided by Hofman (1) and Jenke (2), where one may find the first information on the construction of the middle cerebral artery in the dog. More information about the construction of the middle cerebral artery and its branches in the dog are found in the publication of Hebermehl (3). The author dealt with the construction of the artery only and discussed the topography of its branches on the surface of the

Received:28March 2018

Accepted for publication: 28 April 2020 telencephalon, ignoring its variability. The literature concerning the blood supply to the brain describes the $\operatorname{dog}(4,5)$. These authors mention that the middle cerebral artery is one of the vessels departing from the arterial circle of the brain. In other predatory species similar studies were carried out in the cat (6), in the raccoon dog (7). In the literature, there are publications outlining in detail the cortical branches of the middle cerebral artery. This problem was described by Chadzypanagiotis in cat (8), the author gives nomenclature for individual cortical branches of the artery. Structured descriptions of the construction and the course of the cortical branches of the middle cerebral artery in some predatory species were presented by Wiland (9). In recent years there have been numerous studies 
that discuss the construction of the middle cerebral artery in various mammalian species. This applies to vessels which isolate as a single branch, for example, in red squirrel (10), in ground squirrel (11), in otter (12) and multiple arteries presented in domestic pig (13). These publications stated that cortical branches of the middle cerebral artery in examined species attained the same areas of the telencephalon. The differences occur in the pattern of descent and division of respective cortical branches of the middle cerebral artery. The pattern of division of the middle cerebral artery is affected by how the species has been classified and the pattern of groove-coverage of the cortex. In mammals on the surface of the cortex there is a different pattern of sulci, which can affect the structure of the cortical branches of the middle cerebral artery (14). In vast literature there seem to be missing a paper on the cortical branches of the middle cerebral artery in dog. Considering the discrepancy resulting from respective descriptions and considering new studies, one has decided to investigate the pattern, the division and variation of cortical branches of the middle cerebral artery in dog and to compare the results with the data reported by other authors.

\section{Materials and methods}

The research was performed on 40 brains in dog, namely a total of 80 cerebral hemispheres received from animal shelters in Bydgoszcz. Ethics approval was not required since animals died because of natural reasons. The animal heads were cut off at the height of the $3^{\text {rd }}-4^{\text {th }}$ cervical vertebrae. The arteries were filled with latex introduced with medical syringe into the common carotid artery. This method was described by Godynicki (15). The heads were fixed in a $5 \%$ formalin solution for 3 months, and then decalcified in hydrochloric acid, the skull cavity was opened and brains were taken out. The cerebral hemispheres were photographed and the following were being described: the anatomy, the division pattern and the course of cortical branches of the middle cerebral artery.

\section{Results}

In dog the blood is supplied to the brain with internal carotid arteries (Fig. 1-a) and vertebral arteries.

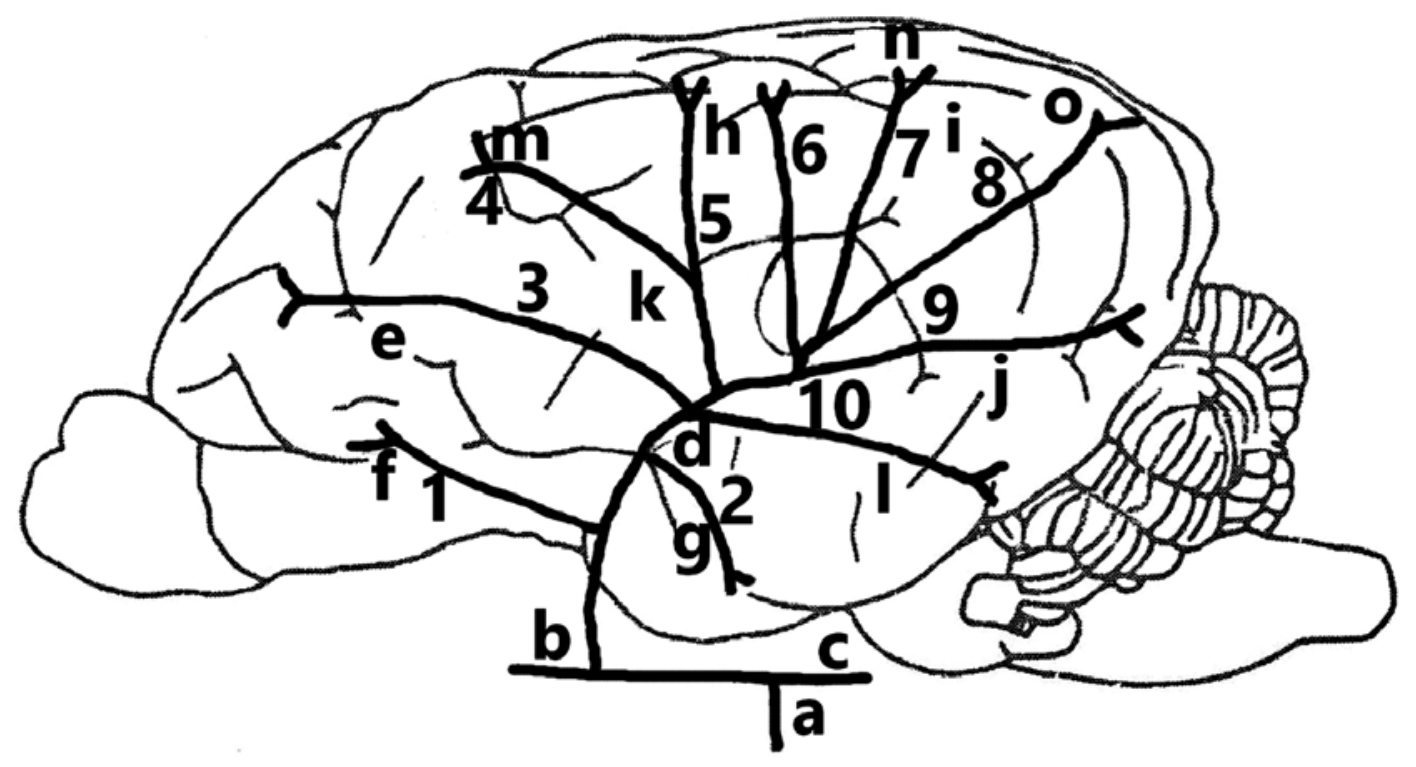

Figure 1: Diagram of the division of the middle cerebral artery on the surface of the cortex in dog

1 - rostral olfactory artery, 2 - caudal olfactory artery, 3 - orbital branch, 4 - inferior frontal branch, 5 - dorsal frontal branch, 6 - rostral parietal branch, 7 - caudal parietal branch, 8 - dorsal temporal branch, 9 - middle temporal branch, 10 - ventral temporal branch, a - internal carotid artery, b - rostral cerebral artery, c- caudal communicating artery, d - Sylvian fissure, e - Presylvian sulcus, f - rostral lateral olfactory sulcus, g - caudal lateral olfactory sulcus, h - rostral Suprasylvian sulcus, i - middle Suprasylvian sulcus, j - caudal Suprasylvian sulcus, $\mathrm{k}$ - caudal external Sylvian sulcus, 1 - middle external Sylvian sulcus, $\mathrm{m}$ - coronary sulcus, $\mathrm{n}$ - marginal sulcus, o - external marginal sulcus. 
The internal carotid artery, having entered the skull cavity and penetrated the dura mater, bifurcates into the rostral cerebral artery (Fig. 1-b) and caudal communicating artery (Fig. 1-c) which, together with their symmetrical vessels form an arterial circle of the brain.

From the initial section of the rostral cerebral artery towards the cortex there separates the middle cerebral artery.

The middle cerebral artery is the strongest vessel supplying blood to the cerebrum. The initial section of the main trunk of the middle cerebral artery goes along the dorsal surface of the optic tract. Then the section gets bended around the piriform lobe and goes through its rostral margin. Further on it runs to the lateral olfactory sulcus and, having passed it, it gets divided. From the initial section of the main trunk of the middle cerebral artery there descend minor central branches supplying blood to olfactory tracts and the piriform lobe. The main trunk of the middle cerebral artery gets divided into a number of cortical branches which run to the specific region of the cerebral hemisphere, supplying blood to specific regions of the brain.

The first permanent branches of the middle cerebral artery which supply both the old and the new cortex are olfactory arteries.

The rostral olfactory artery (Fig. 1-1), having separated from the main trunk of the middle cerebral artery it creates an arch and runs to the rostral part of the lateral olfactory sulcus it can ascend into in various places. Its terminal branches can also appear again from under the lateral olfactory sulcus and then ascend under the cortex surface.

The caudal olfactory artery (Fig. 1-2) ascends into the caudal part of the lateral olfactory sulcus and its terminal branches supply the area of the cortex found under the sulcus.

The other branches of the middle cerebral artery supply the areas of the cortex over the lateral olfactory sulcus. On the cortex towards the frontal lobe there spread three thick branches. As the first one there separates the orbital branch (Fig. 1-3) which is located lowest and it goes towards the region of the Presylvian sulcus where its terminal branches reach the coronary sulcus.

The ventral frontal branch (Fig. 1-4) vascularizes the middle part of the frontal lobe. The vessel goes through the rostral external Sylvian sulcus and the rostral Suprasylvian sulcus towards the coronary sulcus it passes towards the fornix.

The dorsal frontal branch (Fig. 1-5), having separated from the middle cerebral artery at the height of the rostral external Sylvian sulcus, goes up to the region of the cruciate sulcus. The vessel supplies blood to the upper part of the medial surface of the frontal lobe.

The next vessel which runs towards the parietal lobe bifurcates into two branches.

The rostral parietal branch (Fig. 1-6) runs towards the middle external Sylvian sulcus to the marginal sulcus. The terminal twigs of that vessel supply blood to the area of the cortex found under the ansiform sulcus.

The caudal parietal branch (Fig. 1-7) also runs to the region of the marginal sulcus and further on it branches out into smaller vessels. Some of them ascend into the medial Suprasylvian sulcus.

The lateral-caudal surface of the cerebral hemisphere is supplied by the branches of the middle cerebral artery which descend from at various heights and they are referred to as temporal branches.

The dorsal temporal branch (Fig. 1-8) having left the Sylvian fissure, it runs towards the middle Suprasylvian sulcus and further to the upper margin of the cerebral hemisphere. It is uasually the strongest cortical branch of the middle cerebral artery. The branch supplies blood to the upper part of the cortex.

The middle temporal branch (Fig. 1-9) descends a small distance away from the previous branch. The branches of that vessel spread towards the external marginal sulcus. Its terminal branches go onto the surface of the occipital lobe.

The ventral temporal branch (Fig. 1-10) runs to the end of the caudal external Sylvian sulcus. Having passed the caudal part of the sulcus, its branches spread towards the caudal Suprasylvian sulcus. Its terminal branches take part in the supply of a part of the occipital lobe.

Considering the general pattern of the spread the cortical branches of the middle cerebral artery in dog, one shall note that respective sections of those branches can run inside respective sulci and divide, always running towards the cortex areas described.

Analysing the pattern of descent of the cortical branches of the middle cerebral artery in the dog, it was found that from the rostral cerebral artery on $78(97,5 \%)$ cerebral hemispheres there descended a single independent vessel - the middle cerebral artery. Among them on 8 (10\%) hemispheres from the main trunk there descended rostrally with a 
common trunk: the orbital branch, the ventral frontal branch and the rostral olfactory artery. The main trunk of the middle cerebral artery, got onto the surface of the cerebral cortex and formed a common descent for the dorsal frontal branch as well as rostral and caudal parietal branches. Caudally from the main trunk of the middle cerebral artery, with a common trunk there separated the dorsal, middle and ventral temporal branches and the independent caudal olfactory artery. (Fig. 1).

In another $12(15 \%)$ cases there descended rostrally an independent rostral olfactory artery and a common trunk for the orbital, rostral and dorsal frontal branches. The main trunk got onto the surface of the cerebral cortex from the Sylvian fissure and formed a common descent for rostral and caudal parietal branches. Caudally from the main trunk of the middle cerebral artery, with a common trunk there separated the dorsal, middle and ventral temporal branches, whereas the caudal olfactory artery got separated independently from the main trunk of the middle cerebral artery.

On another $12(15 \%)$ hemispheres from the main trunk of the middle cerebral artery there separated rostrally a common trunk for the rostral olfactory artery and for the orbital branch as well as the common descent for the ventral and dorsal frontal branch. The main trunk separated caudally the caudal olfactory artery with a common descent with the ventral temporal branch. The main trunk, having ascended into the Sylvian fissure, on the surface of the cortex it showed a common trunk for rostral and caudal parietal branches as well as for the middle and dorsal temporal branches.

On another $14(17,5 \%)$ cerebral hemispheres from the main trunk of the middle cerebral artery departed the independent rostral olfactory artery and a common departure for the ventral and dorsal frontal branches. Caudally from the main trunk there descended the middle and ventral temporal branch through the common trunk with the caudal olfactory artery. The main trunk, having descended into the Sylvian fissure, got onto the surface of the cortex with a common descent for rostral and caudal parietal branches as well as the rostral and dorsal temporal branch.

On another 12 (15\%) hemispheres from the main trunk the following separated rostrally with a common trunk: the rostral olfactory artery, common trunk for the orbital branch, the ventral frontal branch. The caudal branch was a common descent for the ventral temporal branch and the caudal olfactory artery. The main trunk, having descended into the Sylvian fissure, got onto the surface of the cortex with a common descent for the dorsal frontal branch, rostral and caudal parietal branches as well as the middle and dorsal temporal branch.

On yet another $6(7,5 \%)$ cerebral hemispheres from the main trunk rostrally there separated, with a common descent, the orbital branch, the ventral and dorsal frontal branch and the rostral olfactory artery. Caudally from the main trunk of the middle cerebral artery the following separated with a common descent: rostral and caudal parietal branches as well as the ventral, middle and dorsal temporal branches. The caudal olfactory artery departed independently from the main trunk.

On another $14(17,5 \%)$ cerebral hemispheres from the main trunk of the middle cerebral artery the following departed rostrally with the common trunk: the orbital branch, the ventral frontal branch and the rostral olfactory artery. Caudally from the main trunk of the middle cerebral artery there descended with the common descent: the dorsal frontal branch, the rostral and caudal parietal branches and the dorsal, middle and ventral temporal branches. The caudal olfactory artery departed independently from the main trunk.

On the other $6(7,5 \%)$ hemispheres it was found that from the main trunk of the middle cerebral artery there departed the common trunk for the rostral olfactory artery and the orbital branch, then the common descent for the ventral and dorsal frontal branch. The main trunk got onto the surface of the cortex with a common descent for rostral and caudal parietal branches as well as the dorsal, middle and ventral temporal branch. The caudal olfactory artery departed caudally from the main trunk of the middle cerebral artery as an independent vessel.

On the other $2(2,5 \%)$ hemispheres it was found that from the rostral cerebral artery in dog there bifurcated two independent branches of the middle cerebral artery. Among them the first independent branch from the rostral cerebral artery was the rostral olfactory artery, while the second branch was the main trunk of the middle cerebral artery from which there descended rostrally independently: the orbital branch, the ventral and dorsal frontal branch. Caudally from the main trunk there separated an independent caudal olfactory artery and the ventral temporal branch. The main trunk, having descended into the Sylvian fissure, got onto 


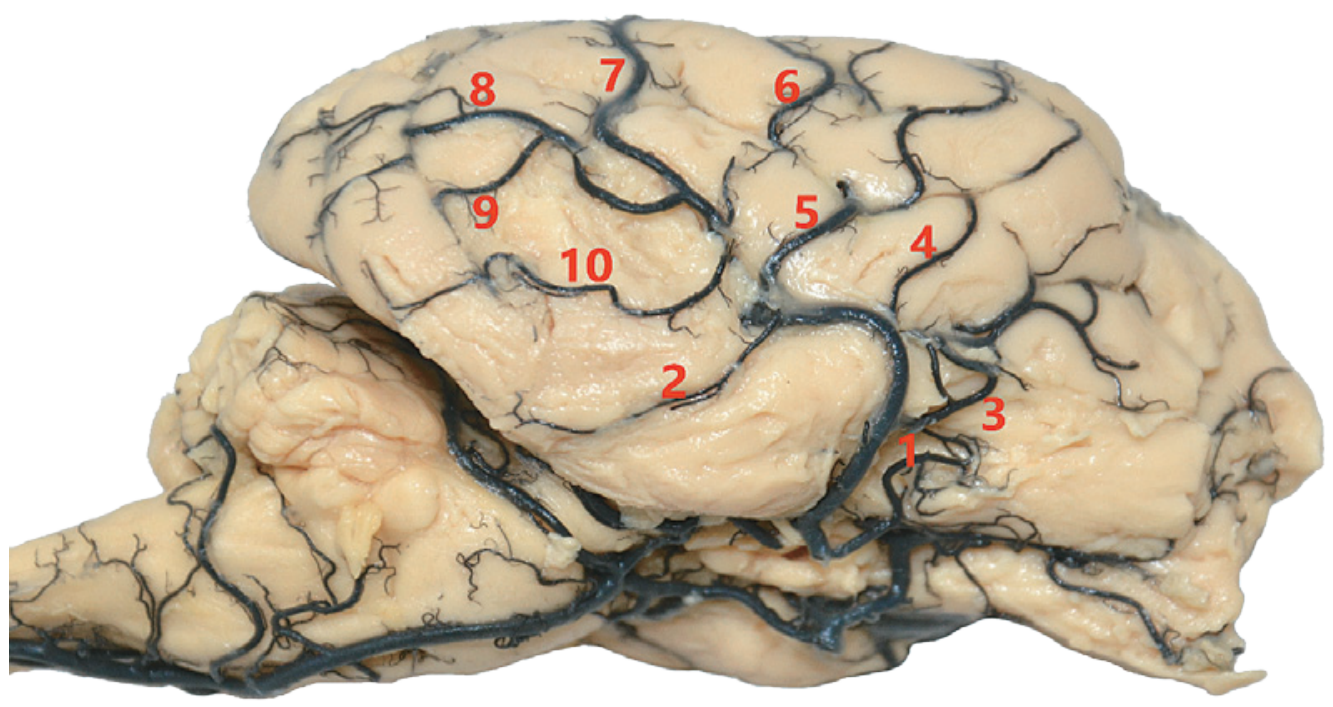

Figure 2: Independent departure of the anterior olfactory artery and the main trunk of the middle cerebral artery from the rostral cerebral artery

1 - rostral olfactory artery, 2 - caudal olfactory artery, 3 - orbital branch, 4 - ventral frontal branch, 5 - dorsal frontal branch, 6 - rostral parietal branch, 7 - caudal parietal branch, 8 - dorsal temporal branch, 9- middle temporal branch, 10 - ventral temporal branch.

the surface of the cortex with a common descent for rostral and caudal parietal branches as well as the common trunk for dorsal and middle temporal branch (Fig.2).

On the other $2(2,5 \%)$ hemispheres it was found that from the rostral cerebral artery in dog there bifurcated two independent branches of the middle cerebral artery. Among them the first independent branch from the rostral cerebral artery was the rostral olfactory artery, while the second branch was the main trunk of the middle cerebral artery from which there descended rostrally independently: the orbital branch, the ventral and dorsal frontal branch. Caudally from the main trunk there separated an independent caudal olfactory artery and the ventral temporal branch. The main trunk, having descended into the Sylvian fissure, got onto the surface of the cortex with a common descent for rostral and caudal parietal branches as well as the common trunk for dorsal and middle temporal branch (Fig.2).

\section{Discussion}

The middle cerebral artery supplies blood to the greatest region of the cerebrum and is the most shaped branch extending from the rostral cerebral artery. In dog the middle cerebral artery supplies the same areas of the brain as in the mammalian species studied so far. The discrepancies concern mostly its division into respective branches. Chadzypanagiotis (8), describing the cortical branches in cat, differentiated between the branches supplying the old cortex, the branches on the border of the old and the new cortex as well as the branches for the new cortex. In dog the arteries supplying the old cortex are minor branches onto the piriform lobe and olfactory tracts. On the border of the old and the new cortex there are found the rostral and caudal olfactory arteries. In dog the rostral olfactory artery in $2.5 \%$ of the cases was a vessel which descended independently from the rostral cerebral artery. On the other cerebral hemispheres it was a vessel which got separated independently from the main trunk of the middle cerebral artery in $32.5 \%$ of the cases. In $22.5 \%$ of the cases it formed a common departure with the orbital branch. On the $35 \%$ of the cerebral hemispheres it was one of the branches descending from the common trunk of the middle cerebral artery which gave rise to the orbital branch and the ventral frontal branch. In the other $7.5 \%$ cases the rostral olfactory artery demonstrated a common descent with the orbital, ventral and dorsal frontal branches. 
The caudal olfactory artery, on the other hand, in $45 \%$ of the cases was a vessel which descended independently from the rostral cerebral artery. On $37.5 \%$ the caudal olfactory artery separated with a common descent with the ventral temporal branch. In the other $17.5 \%$ hemispheres the caudal olfactory artery was one of the branches of a common trunk for ventral temporal branch. In another $20 \%$ of the cases it was one of the branches of the common trunk for the ventral and middle temporal branches.

The other cortical branches of the middle cerebral artery can be divided into a group of frontal, parietal and temporal branches. In dog, similarly as in other Carnivora species there occur eight main vessels which supply blood to the area of the new cortex of the cerebrum.

Besides, respective cortical branches can descend from the main trunk of the middle cerebral artery with a common descent. Such cases of descent were reported by Wiland (9), Skoczylas et al. (12) as the rostral, dorsal and caudal middle cerebral artery. In dog the rostral middle cerebral artery has been presented as a common trunk for frontal branches and it occurred in $32.5 \%$ of the cases investigated, the dorsal middle cerebral artery was described as a common trunk for parietal branches, which was observed in $17.5 \%$ of the cases. The caudal middle cerebral artery as a common trunk for temporal branches was found in $25 \%$ of the cases.

In dog the dorsal middle cerebral artery occurred as the lowest percentage of the cases, however, here the rostral middle cerebral artery dominated. Making a comparison of the present results with those reported by Wiland (9) in American mink, and by Skoczylas et al. (12) in otter one can state the dorsal middle cerebral artery was reported as the lowest percentage of the cases. In dog, similarly as in the other animal species studied, the parietal branches have developed poorest. On the surface of the cerebrum the best developed are the frontal branches of the middle cerebral artery.

From the description of the structure of the middle cerebral artery in the publications by Aydin et al. (11), Ozudogru et al. (16), Skoczylas et al. (12) in the ground squirrel, common fox and otter one can see that it is usually a single vessel descending from the rostral cerebral artery. The vessel, having passed the lateral olfactory sulcus, gets divided along its course into respective cortical branches. In the material investigated such a pattern of division of the middle cerebral artery was found in $97.5 \%$ of the cases. In dog there were identified the cases of descent from the rostral cerebral artery of two independent arterial trunks in $2.5 \%$ of the cases. The second independent branch from the rostral cerebral artery was the rostral olfactory artery. In other mammalian species the presence of two independent descents of the branches of the middle cerebral artery was found in rabbit in $31.4 \%(17)$, in wild rabbit (18) in $36.5 \%$ of the cases, in raccoon dog (7) in $18.6 \%$ of the cases.

The present research show that observed in dog the division of the middle cerebral artery into the same branches or their groups, like in the other mammalian species investigated so far is, according to Wiland (19), a result of genetic limitations.

\section{References}

1. Hofmann M. Zur vergleichenden Anatomie der Gehirn und Ruckenmarksarterien der Vertebraten. Zeitschr Morphol Anthrop 1900; 2: $247-$ 320.

2. Jenke TW. Die Gehirnarterien des Pferdes, Hundes, Rindes und Schweines verglichen mit denen des Menschen : Diss. Dresden, 1919.

3. Hebermehl KH. Zur Topographie der Gehirngeafasse des Hundes. Anat Histol Embryol 1973; 2: 327-53.

4. Wiland C. Variations of the basilar arteries of the brain in dogs. Folia Morphol Wars 1973; 32: 63-70.

5. Tanuma K. A morphological study on the cirle of Willis in the dog. Okajimas Folia Anat Japon 1981; 58: 151-76.

6. Chadzypanagiotis D, Kubasik A. The arteries supplying blood to the brain of a cat. Folia Morphol Wars 1968; 27: 477-87.

7. Brudnicki W, Wiland C, Jabłoński R. Basilar arteries of the brain in raccoon dog (Nyctereutes procyonoides Gray). Arch Vet Pol 1994; 34(1/2): $141-7$.

8. Chadzypanagiotis D. Arteries on the surface of the cerebral hemisphere in the cat. Folia Morphol Wars 1975; 32: 385-99.

9. Wiland C. Comparative studies of cortical branches of the middle cerebral artery in some predatory species (Carnivora). Sci J ATR Bydg 1991; 44: 1-52. 
10. Aydin A. The morphology of circulus arteriosus cerebri in the red squirrel (Sciurus vulgaris). Vet Med 2008; 53(5): 272-6.

11. Aydin A, Ozkan ZE, Yilmaz S, et al. The morphology of the circulus arteriosus cerebri in the ground squirrel (Spermophilus citellus). Vet Med 2009; 54(11): 537-42.

12. Skoczylas B, Brudnicki W, Nowicki W, et al. The cortical branches of the middle cerebral artery in the otter (Lutra lutra). Vet Med 2012; 57(6): 282-6.

13. Skoczylas B. Cortical branches of middle cerebral artery in domestic pig (Sus scrofa $f$. domestica). Electron J Pol Agric Univ Vet Med 2000; 3: e1-6.

14. Brauer K, Schaber W. Katalog der sangetiergehirne. Jena : Gustaw Fisher Verlag, 1970.
15. Godynicki S. Use of LBS 3060 Latex in anatomic preparations. Folia Morphol Wars 1971; 30(4): 601-3.

16. Ozudogru Z, Can M, Balkaya H. Macro-anatomical investigation of the cerebral arterial circle (circle of willis) in red fox (Vulpes vulpes Leunnoleus, 1758). J Anim Vet Adv 2012; 11(16): 2861-4.

17. Wiland C. Basilar arteries of the brain in the domestic rabbit. Folia Morphol 1968; 27: 288-95.

18. Brudnicki W, Nowicki W, Skoczylas B, et al. Arteries of the brain in wild European rabbit Oryctolagus cuniculus (Linnaeus, 1758). Folia Biol 2012; 60 (3/4): 189-94.

19. Wiland C. Factors affecting the variability of the brain base arteries in mammals. Zool Rev 1974; 18: 400-16.

\section{OŽILJENOST TELENCEFALONA PRI PSIH (Canis lupus f. familiaris)}

\section{K. Kirkiłło-Stacewicz, W. Nowicki, J. Wach}

Izvleček: : Študije ožiljenosti možganov pripseh so bile izvedene na 80 možganskih poloblah. Ugotovljeno je bilo, da je srednja možganska arterija najmočnejša žila, ki dovaja kri v možgane. Arterija se razdeli na deset stalnih vej. Dve vohalni arteriji napajata predel možganov, ki se nahaja na meji med staro in novo možgansko skorjo. Ostalih osem arterij oskrbuje področje nove skorje: tri veje, ki potekajo do prednjega režnja, dve veji, ki potekata v parietalni reženj in tri temporalne veje, usmerjene $v$ temporalno področje. Čelne, parietalne in temporalne veje so se razvejale neodvisno od glavnega debla srednje možganske arterije, ali pa so tvorile skupno deblo. Običajna debla za posamezne skupine vej so opisana kot rostralna, dorzalna in kavdalna srednja možganska arterija. V 2,5 odstotkih primerov sta obstajali dve neodvisni veji srednje možganske arterije, ki izhajata iz rostralne možganske arterije.

Ključne besede: možganske arterije; pes; ožiljenost; raznolikost 